\title{
Challenges in the Integration of Light Rail and Land Use: A Case Study of Yizhuang Line in Beijing
}

\author{
Haishan Xia $^{1}$ Chen Shen ${ }^{2}$ Chun Zhang ${ }^{1,3} \cdot$ Xinhao Wang $^{3,4} \cdot$ Daizong Zhang $^{1}$
}

Received: 1 February 2017/Revised: 21 March 2017/Accepted: 25 March 2017/Published online: 18 April 2017

(c) The Author(s) 2017. This article is an open access publication

\begin{abstract}
Transit-oriented development (TOD) is advocated by urban planners as a tool to promote transportation and land use integration, and it has especially been applied in new town developments in Chinese cities. Since 2000, urban metro system construction in Beijing has accelerated and many new towns in suburban areas have emerged due to rail transit connections with the central city. This paper is a case study of Yizhuang new town, which is located in the southeast suburban area of Beijing. It explores whether light rail is successful in promoting transportation and land use integration. First, by comparing the land use within a $1 \mathrm{~km}$ radius of three rail stations, findings suggest that the TOD model in terms of land use may not be implemented. Second, by tracing land use changes over time, we found that commercial functions are critical to support TOD development. Third, the mismatch of urban functions between low-skilled labor employment opportunities and high-skilled residential neighborhoods emphasizes the failure of planned reverse commuting patterns. In conclusion, our findings suggest that without a proper land use policy, TOD based on light rail only may not be a successful model in the case of Yizhuang new town. The
\end{abstract}

Chun Zhang

zhangc@bjtu.edu.cn

1 School of Architecture and Design, Beijing Jiaotong University, Beijing, China

2 School of Civil Engineering, Beijing Jiaotong University, Beijing, China

3 UC-BJTU Future City Co-Lab, Beijing, China

4 School of Design, Architecture, Art and Planning, University of Cincinnati, Cincinnati, OH, USA

Editors: Haishan Xia, Chun Zhang policy implication is that the planning code of land use should be more flexible and adaptable, in order to promote the integration of transportation and land use in a synergetic way.

Keywords Transit-oriented development · Light rail · Integration · Beijing · Yizhuang

\section{Introduction}

The concept of transit-oriented development (TOD) can be traced to American cities around the turn of the twentieth century when trams, buses, and streetcars became the dominating mode of urban transportation. Most urbanized areas were situated along transit lines. As automobiles became the main mode of transportation, especially after World War II, middle-class families consequently moved to suburban areas, leading to a substantial decline of public transportation facilities. Driving to work gradually becomes a necessary part of typical American life. In response to the problems posed by increased car use, such as traffic congestion, increased energy consumption, and air pollution, several American cities invested in public transit such as light rails.

Under these circumstances, TOD emerged as the main model of transportation development [1]. TOD advocates that neighborhoods around transit stations should have high-density and mixed land uses [2, 3]. Peter Calthorpe popularized the term TOD in his 1993 book, "The New American Metropolis," to encourage public transportation and mixed land use in nearby neighborhoods (Calthorpe 2001). Other scholars later developed more TOD definitions and adopted TOD principles in their practice (Table 1). For example, Bernick and Cerbvero pointed out 
Table 1 Literature on TOD in the USA

TOD in the USA
$\begin{gathered}\text { Peter Calthorpe [1] } \\ \text { objectively } \\ \text { TOD is a compact, functional mix of community, with a public transport site for community centers, through } \\ \text { a reasonable design, to encourage people to use less cars, more public transport. Bus stations are the } \\ \text { centers of communities within a 400-m radius }\end{gathered}$
$\begin{gathered}\text { TOD is similar to the new development (neo-traditional development, NTD); it aims to improve use of high- } \\ \text { capacity transportation, as well as new city development mode, mixed use of land, and diversification of } \\ \text { architectural design to replace the monotonous form of land use }\end{gathered}$
$\begin{gathered}\text { ToD has a relatively high density of development, including living, employment, commercial, and public } \\ \text { facilities, such as the function of mixing in a bus or rail transport site within walking distance }\end{gathered}$
$\begin{gathered}\text { Transportation [4] } \\ \text { Tralifornia Department of }\end{gathered}$
$\begin{gathered}\text { ToD is a moderate- or high-density land use around the main public transportation site, usually will include } \\ \text { living, employment, commercial facilities within the scope of mixed arrangement, and is suitable for }\end{gathered}$
walking, and the coordination of public transport facilities

that bus stations should be within $1 / 4$ miles from residential locations in order to create a compact and multifunctional neighborhood [4]. Similar to planned unit development (PUD) and traditional neighborhood planning (TND), TOD promotes walkability [5]. The New Urbanism movement in the 1990s removed debate of whether or not to promote TOD in urban design and neighborhood planning. Empirical studies support the advantages of TOD neighborhoods compared with other suburban neighborhoods: Residents drive less by $33 \%$ [6] and have more social interaction with neighbors [7] than those in lowdensity, cul-de-sac neighborhoods. Many state transportation bureaus also adopted TOD. For example, Maryland Department of Transportation promotes high-density development, accessible facilities and amenities, and bus or rail transportation systems at walking distance [8]. California Department of Transportation highlights land use development and commercial facilities around transportation facilities and promotes a residential-employment-commercial integrated land use model [9]. TOD not only improves the use of high-capacity transportation, but also encourages mixed land use and building style diversification. In conclusion, TOD provides more travel options of a neighborhood the choices of life style. It helps to reduce car use and thus also decreases greenhouse gas emissions and improves air quality. According to the New Urbanism advocators, TOD also promotes healthier and sustainable life style because it encourages citizens to shift from driving to walking [10].

TOD was introduced in China in the late 1990s against the background of rapid urbanization and suburbanization [11]. While large-scale affordable housing communities emerged on the outskirt of large cities [12], urban rail transportation infrastructure became critical given that it provides the essential connection between suburban housing and urban center jobs [13]. In particular, among middle- and low-income groups living in affordable housing, rail transportation became the main affordable travel mode supporting large volumes of mass transit.

TOD has been widely used in China and remains popular in urban planning practice, especially with the acceleration of rail transit development. In contrast with most of American cities, Chinese cities generally have higher density, and as such they are very suitable cases for the application of the TOD model [8]. Also, the car-oriented development model does not have a deep-rooted historical influence in most Chinese cities, which makes the TOD principles more easily accepted by Chinese planners and decision makers [14].

On a national scale, many cities emphasize TOD in their comprehensive planning, such as Beijing, Dalian, Shenzhen, Wuhan, and Tianjin [15]. In 2016, the Ministry of Housing and Urban-Rural Development (HURD), the National Development and Reform Commission, and the Ministry of Finance jointly selected 127 towns in China as the first group of national featured towns [16]. The TOD model was highlighted by both urban planners and government officials in the featured town planning and urban designs.

Some scholars point out difficulties in fully realizing the TOD model in the short run. For example, in cases of extremely rapid urbanization, public transit facility construction usually lags far behind mass-produced suburban housing projects [17]. An extremely high passenger volume during peak hour is described as a failure of the fulfillment of TOD [17].

To contribute to the literature of assessing TOD in the context of contemporary urbanization in China, this paper analyzes the connection of urban rail transit and urban planning, using the light rail line in Yizhuang as a case. Yizhuang is selected because it is the only New Town connected to the city center with a rail transit 
infrastructure, which makes Yizhuang a suitable case to assess the success of the TOD model. The purpose of the study is to clarify use and expectations of transit-oriented development in China.

\section{Methods and Data}

The study starts with a description of the Yizhuang development and the purpose of developing the Yizhuang light rail line. Land use and travel data in three stations in Yizhuang are analyzed. The analysis is conducted at three scales. At the microscale, it identifies the land use types around metro stations to evaluate the matching degree between transportation and land use. At the mesoscale, it identifies the layout of urban functions along the urban rail transit lines to evaluate the coordination of different urban functions. At the macroscale, it examines the commuting pattern to evaluate the effectiveness of the urban rail transit network on the job-housing spatial distribution (Fig. 1).

Data used in the study include the Beijing comprehensive plan, obtained from Beijing Municipal Government, the detailed planning from Beijing Urban Planning Information Center. The land use image from the years of 2008 and 2015, outlining the before and after situations of the construction of the three stations, is collected from the Beijing Urban Planning Bureau and Google map images.

A small sample survey was conducted near the three metro stations. In total, 150 questionnaires were handed out and 108 valid questionnaires were collected. The structured questionnaire asked about the personal information, commuting behavior, employment, and residential experiences among the respondents. Land use data within $1 \mathrm{~km}$ of the three Yizhuang stations are extracted and classified using the China Urban Planning land use classification system. The 1-km distance is based on average walking distance to metro stations in Beijing.

\section{Results and Discussion}

\subsection{New Town Development Plan and Light Rail Line in Yizhuang}

Triggered by the preparation for the Olympics in 2008, the urban rail transit system in Beijing has experienced dramatic expansion. Since the turn of the century, it has increased from 2 lines of $51.4 \mathrm{~km}$ to a well-established network including 19 lines, 288 stations, and $574 \mathrm{~km}$ in 2015. According to the latest Beijing comprehensive plan in 2004, the initiative of massive rail transportation construction was decided upon to support the new urban form plan, namely "two-axis, two-belt, and multiple centers" [18]. In particular, three suburban new towns Tongzhou, Shunyi, and Yizhuang were designed as three new job centers of the polycentric structure.

This paper is a case study of the light rail system in Yizhuang New Town, because it is the only national level economic development and also undertakes the task of evacuating industries. Unlike other new towns such as Tongzhou and Yizhuang, Yizhuang is designed to be a suburban job center. It makes the light rail in Yizhuang a unique case, which is designed as a reverse commuting urban metro line. Historically, Yizhuang was a small rural village until 1994 when it was selected as a National Economic Development Zone. According to the 2004 Beijing master plan, the Yizhuang New Town was planned
Fig. 1 Research framework of integrated development between rail transit and land use
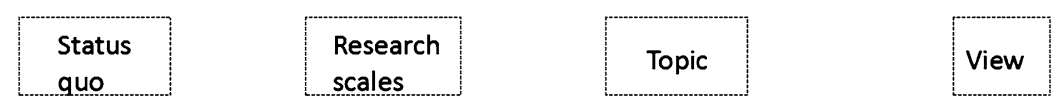

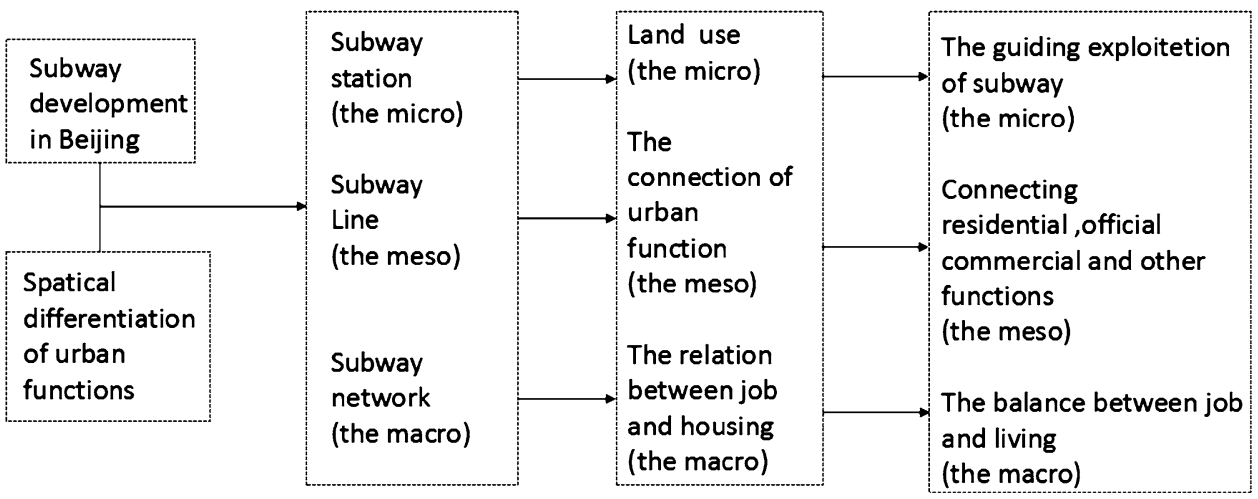


as a high-tech industrial center and an advanced manufacturing center, with a total population of 300,000 in 2010 and estimated population of 700,000 in 2020; it is the result of evacuation of both jobs and population from the city center. The light rail line is designed to be the essential transportation facility to draw employees from urban center to economic development zone in the new town, achieving the objectives of population evacuation.

The Yizhuang line commenced operation in 2010 and functions as an extension of metro line 5. Yizhuang light rail starts at the Songjiazhuang metro station where it connects to the subway line 10 , stretching $23.3 \mathrm{~km}$ toward southeast to the edge of Tongzhou district. It has 13 stations and passes through the central area of Yizhuang New town (Fig. 2).

Along the Yizhuang light rail, three stations are inside Yizhuang New Town. Wanyuanjie station is one of the earliest stations in the old administrative center of Yizhuang. Rongjingdongjie station is near the new administrative center. Jinghailu station is located in the new developed area near the end terminal (Fig. 3).

Both the 2004 master plan and detailed planning highlight TOD principles, which advocates arranging land use density and land use types according to the distance to light rail stations. Commercial buildings are located in the inner circle just outside the stations, office and residential buildings constitute the outer layer of the circle along streets, while industrial buildings are located on the periphery of the $1-\mathrm{km}$ radius area. The intent of the planning is to integrate transportation infrastructure with surrounding land uses and facilities and to provide better accessibility and convenience for rail transit users.

\subsection{Comparison of Land Use Between Plan and Reality}

Microscale comparison of the land use within a $1-\mathrm{km}$ radius around the metro station highlights the differences between plan and reality. Although the original plan was prepared according to TOD principles, not all of the actual land use follows the plan. Figure 4 illustrates the planned land uses in the 2004 master plan and the observed land uses in 2015 for the three stations. A visual comparison shows that the development in Wanyuanjie (Fig. 4a) and Rongjingdongjie (Fig. 4b) stations mostly followed the plan. However, Jinghailu station (Fig. 4c) turned out to be a low-density, manufactural function-oriented industrial zone.

The inconsistency between planned and actual land uses reveals the difference in TOD performance in new town development in Chinese cities. Without suitable planning implementation tools, the area around light rail station cannot naturally grow in a TOD way. It also shows that in the early stage of new town development, new development may not automatically take place near transportation facilities, which may have negative consequences for
Subway network 2000

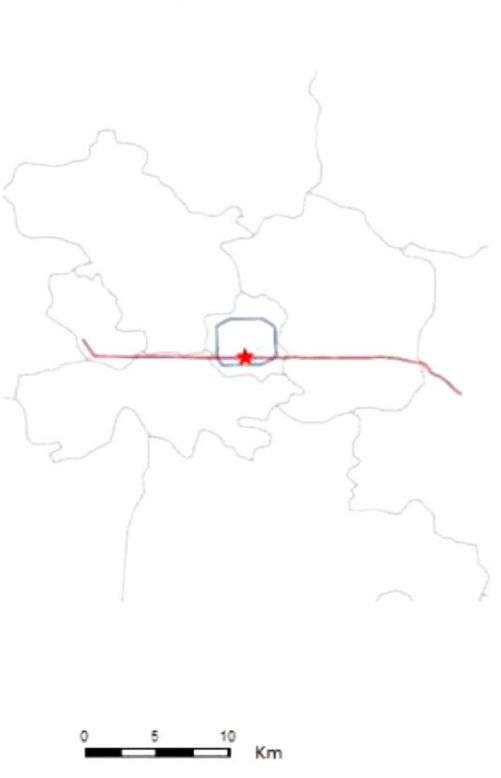

Subway network 2010

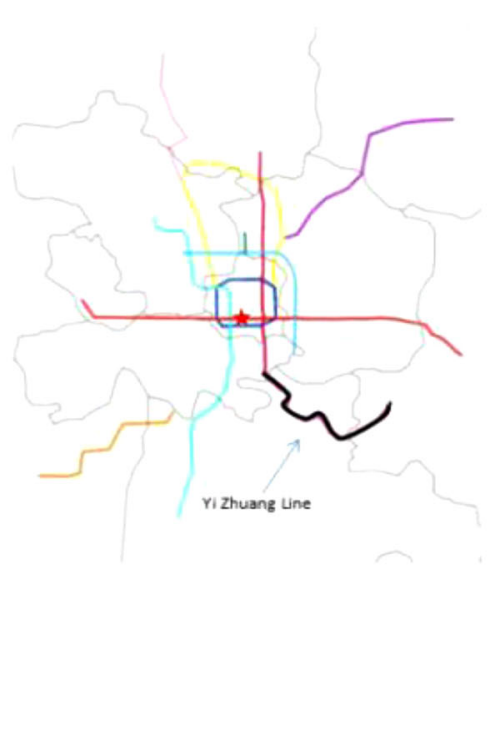

Subway network 2015

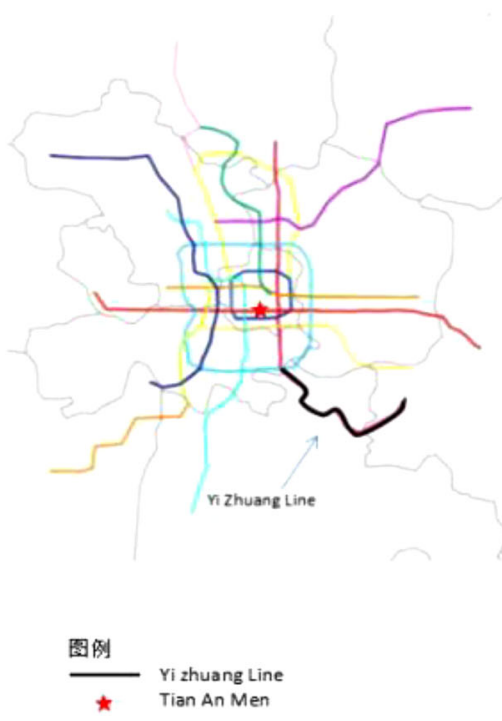

Fig. 2 Rapid development of urban rail transportation in Beijing and Yizhuang light rail line 
Fig. 3 Location and study area of the $1 \mathrm{~km}$ land use around station

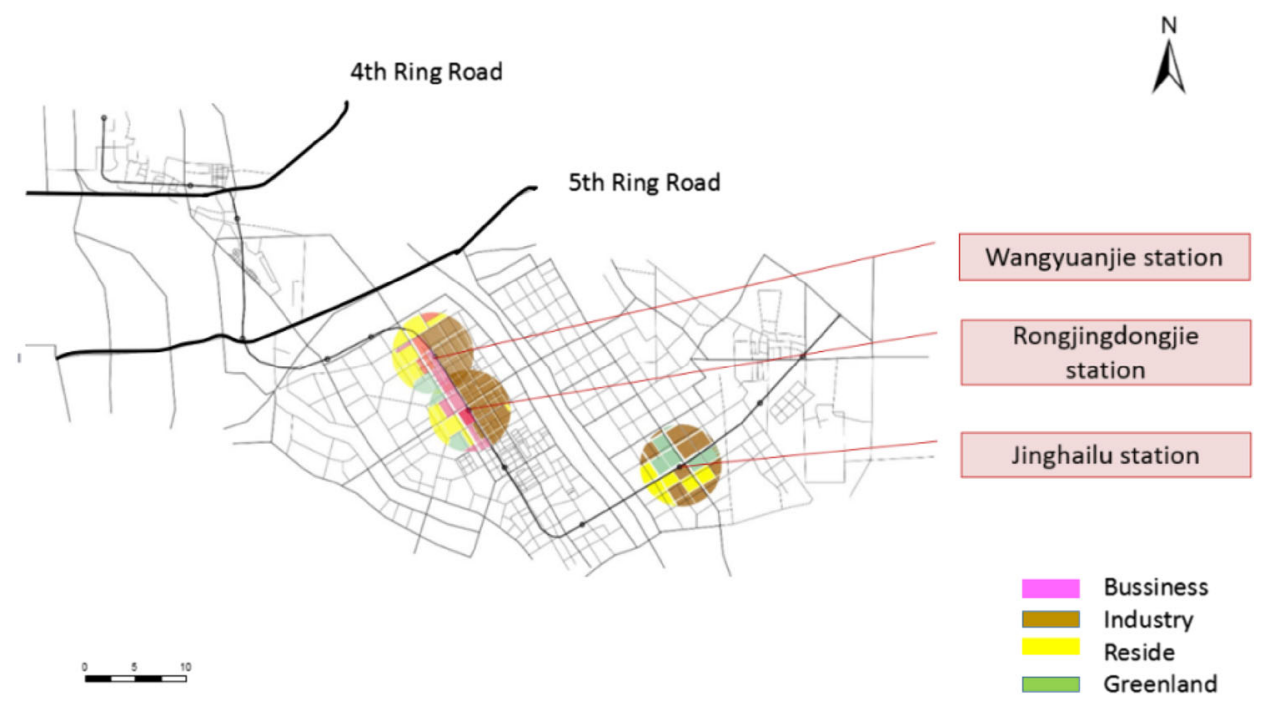

future TOD planning. The failure in fulfilling the TOD model around Jinghailu station, suggests that industrialoriented development may not effectively comply with the TOD model in Chinese cities.

\subsection{Land Use Change Over Time Around Metro Station}

Transportation planners and urban planners tend to assume that with the opening of an urban metro station, the land use of the surrounding area will develop naturally according to planned TOD models, and that any mismatch between planning and reality is only temporary. In particular, commercial facilities and amenities are usually neglected in the early stage of planning. By comparing the land use pattern in 2008 and 2015 by Google map, this section traces the land use change over time around urban rail stations.

By examining land use change from 2008 to 2015 within a $1-\mathrm{km}$ radius around three stations, our findings suggest that a certain proportion of commercial land is critical for the TOD model (Table 2). For example, there are $14.52 \%$ commercial land within the $1-\mathrm{km}$ radius around Wanyuanjie, which provides enough space for various facilities and amenities such as shopping centers, convenient stores, restaurants, bars, and cafes. In contrast, commercial land proportion is only $3.62 \%$ near Rongjingdongjie. In the last case of Jinghailu, there is no commercial land around the station which makes boring landscape. The comparison among three stations shows the importance of commercial land as the attractive core in TOD model.

Land use change from 2008 to 2015 reflects different influence of urban rail stations. In the area around the first case, Wanyuanjie commercial land increased between 2008 and 2015, making it into a multi-functional center including business, commercial, and recreation (Fig. 5a). In the case of Wenjindongjie, residential and administrative land increased, making it a semi-employment, semi-residential area. At the Jinghailu station, industrial land increased making it a manufacturing center (Fig. 5b). These findings show that even with similar urban rail transit stations along the Yizhuang line, the impact of transportation facilities on land use change may be significantly different (Fig. 5c). With suitable urban planning and proper urban design, more facilities and amenities may develop around rail stations with time and thus increase the livability and vitality of the neighborhood. However, these facilities and amenities might not naturally appear without featured public space reserve ahead and a flexible zoning code.

\subsection{Urban Functions and Commuting Pattern as Suburban New Town}

As one of the suburban new towns, Yizhuang is planned to be an employment center which enables the evacuation of both industry and population from the central city. The light rail line is the essential transportation facility to draw employees from the urban center to the economic development zone in the new town, achieving the objectives of population evacuation.

However, in the perspective of urban functions, there is large low-density industrial land concentrated along the light rail line, which is not conducive in making Yizhuang New Town an attractive employment center (Fig. 6), as it mainly provides low-skilled job opportunities, while failing to provide job opportunities for the high-skilled residents in the surrounding neighborhoods. Thus, as an economic and technological development zone, it attracts employees either from the urban center or local neighborhood. 


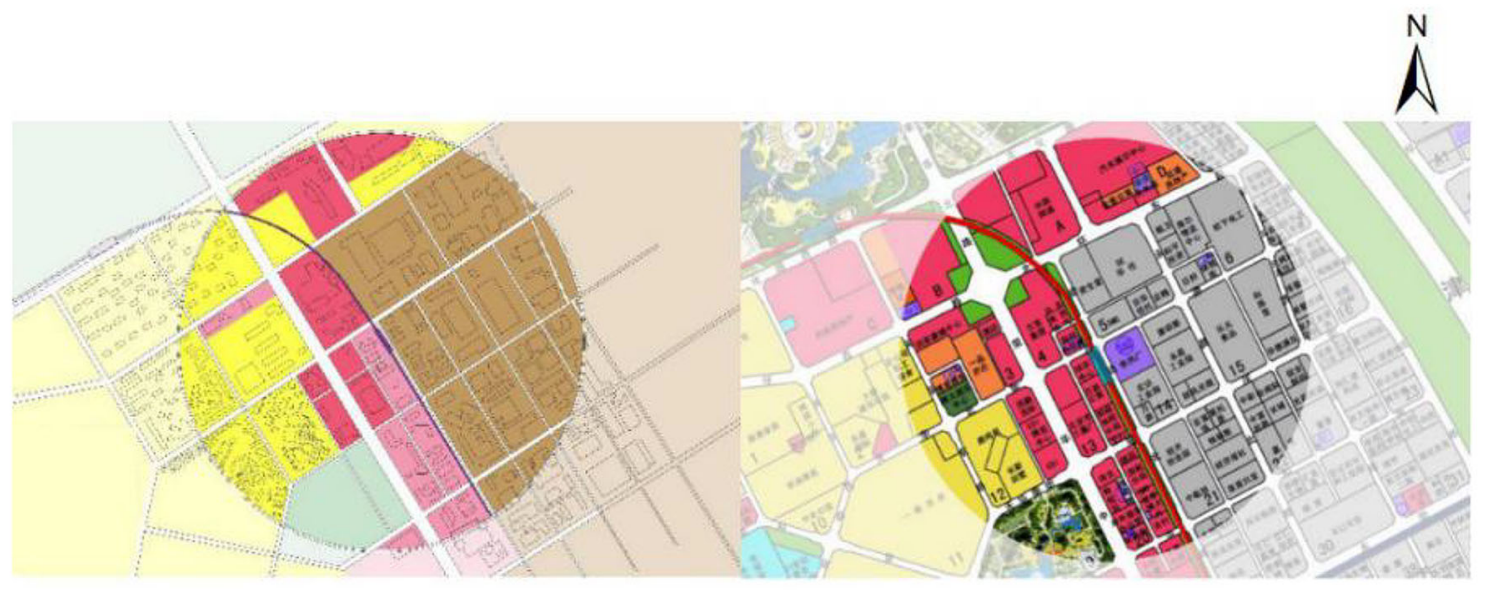

(a)

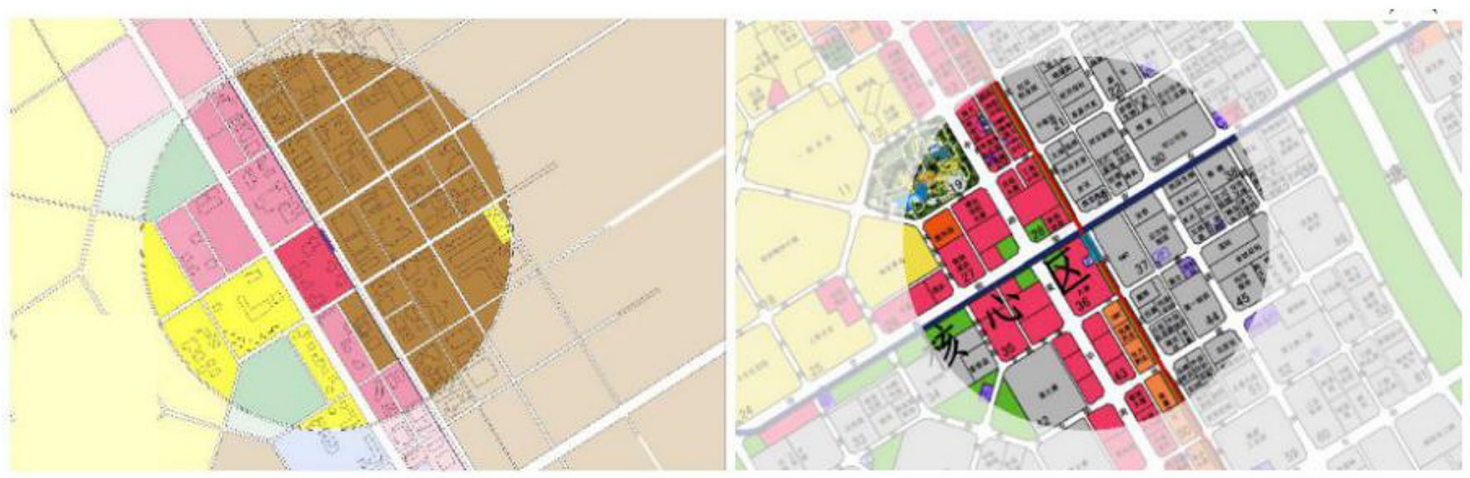

(b)

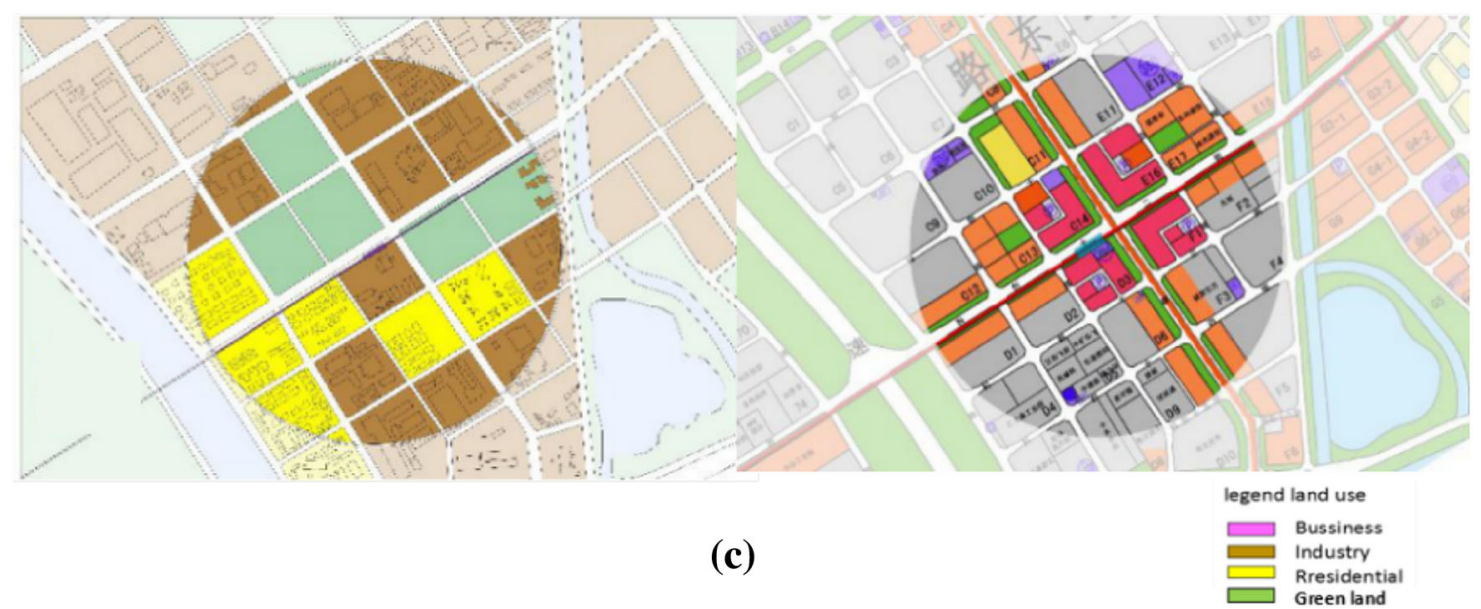

Fig. 4 Actual (left) and planned (right) land use around three light rail stations

Table 2 Land use surrounding three stations in 2015

\begin{tabular}{lllll}
\hline Land use station & Commercial (\%) & Administrative (\%) & Residential (\%) & Industrial land (\%) \\
\hline Wanyuanjie & 14.52 & 7.52 & 27.67 & 41.15 \\
Rongjingdongjie & 3.62 & 17.25 & 18.71 & 49.45 \\
Jinghailu & 0 & 0 & 23.82 & 44.28 \\
\hline
\end{tabular}




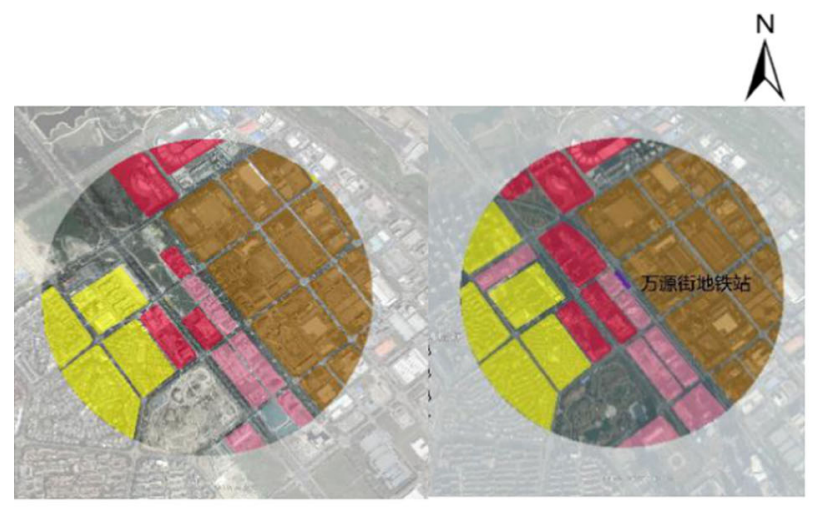

(a)

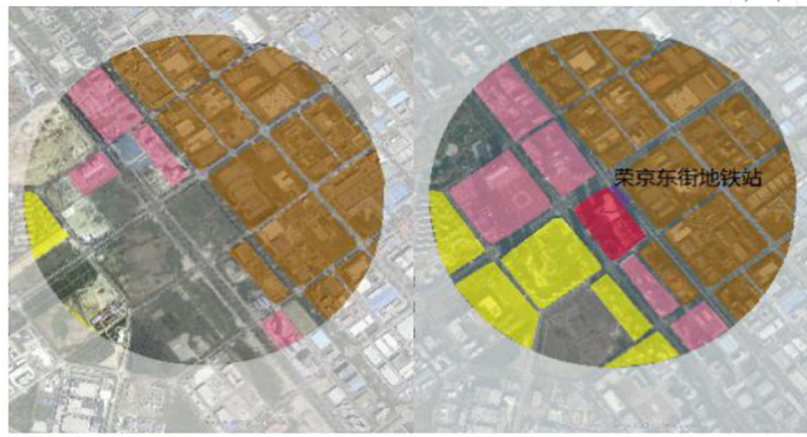

(b)

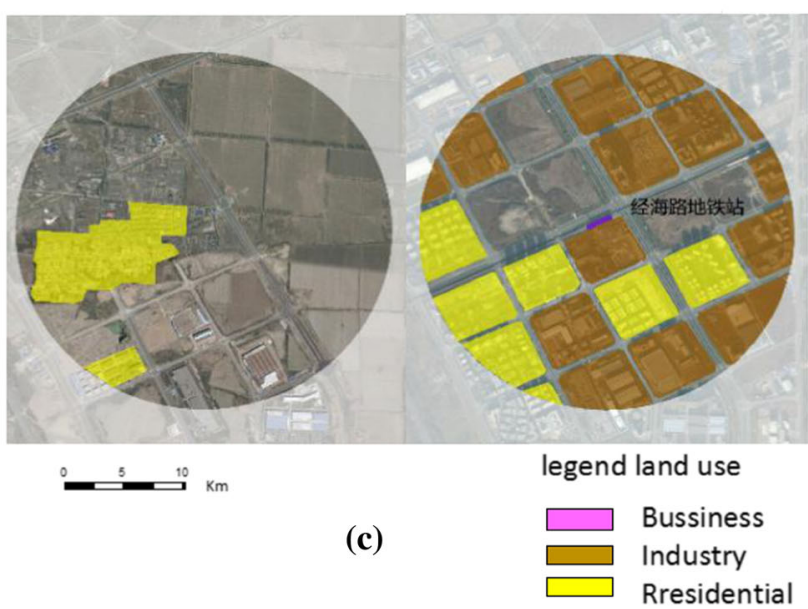

Fig. 5 Land use in 2008 (left) and 2015 (right) around three light rail stations

The findings from the small-scale questionnaire collected near the light rail stations support the assumption of a mismatch between low-skilled job opportunities and high-skilled residential neighborhood. Among the total 108 samples, $50.9 \%$ of local residents still work in the city center, while in terms of local employment rate, $46 \%$ of local employees come from other, more distant suburban neighborhoods (Fig. 7). The gap between the ideal and the actual commuting patterns implies that the objective of making Yizhuang New Town a job center has not been successful. Ideally, most local residents should commute in a reverse way to the suburban industrial areas, while a limited volume of local residents commute to the city center. However, the actual situation in Yizhuang suggests that most of the residents still commute to the urban city center for employment, while the industrial-oriented economic development zone attracts only a small proportion of commuters from the city center and surrounding suburban neighborhoods (Fig. 7).

In addition, the small-scale questionnaire survey reveals that the Yizhuang light rail line does not fulfill its purpose to transport citizens from the center to the suburbs. In contrast, residents living in the suburb instead choose the subway to transit to the city center for employment. The mismatch between the ideal and real commuting patterns reveals the failure of light rail as a method to evacuate job opportunities to Yizhuang New Town. Instead, the findings of this case study suggest that the light rail line aggravates traffic congestion of the city center, in conflict with the original master plan of Beijing.

\section{Conclusion}

While transit-oriented development originated in the USA, it is also promoted in China, especially for new town developments. With the trend of rapid urban rail transportation construction, it is generally assumed that the existence of transportation facilities will automatically lead to a TOD model. Selecting Yizhuang New Town in suburban Beijing, this paper evaluates the performance of light rail in Yizhuang in supporting the integration between transportation and land use. This paper will also explore whether attractive job center emerges and evacuates population and jobs as the master plan advocated in the case of Yizhuang.

Yizhuang in Beijing is a suitable case for studying the impact of light rail systems on land use in a suburban new town. The Yizhuang light rail line is planned to support the city center and near-suburban residents commuting to far suburban new town. Exploring the GIS-based spatial analysis, this paper compares the planned and actual patterns of land use within a 1-km radius area of three stations along the Yizhuang line. It finds that the gap between plan and reality in the land use pattern is significant, especially around the Jinghailu station at the end of the rail line, where an industrial-oriented model is adopted. The land use change over time also reveals the importance of commercial land in supporting a successful TOD model. Without attractive facilities and amenities provided by commercial land, the daily needs of resident and employees are not met. Additionally, the planned reverse commuting pattern fails to realize the aims of evacuation 
Fig. 6 Land use map around light rail line of Yizhuang

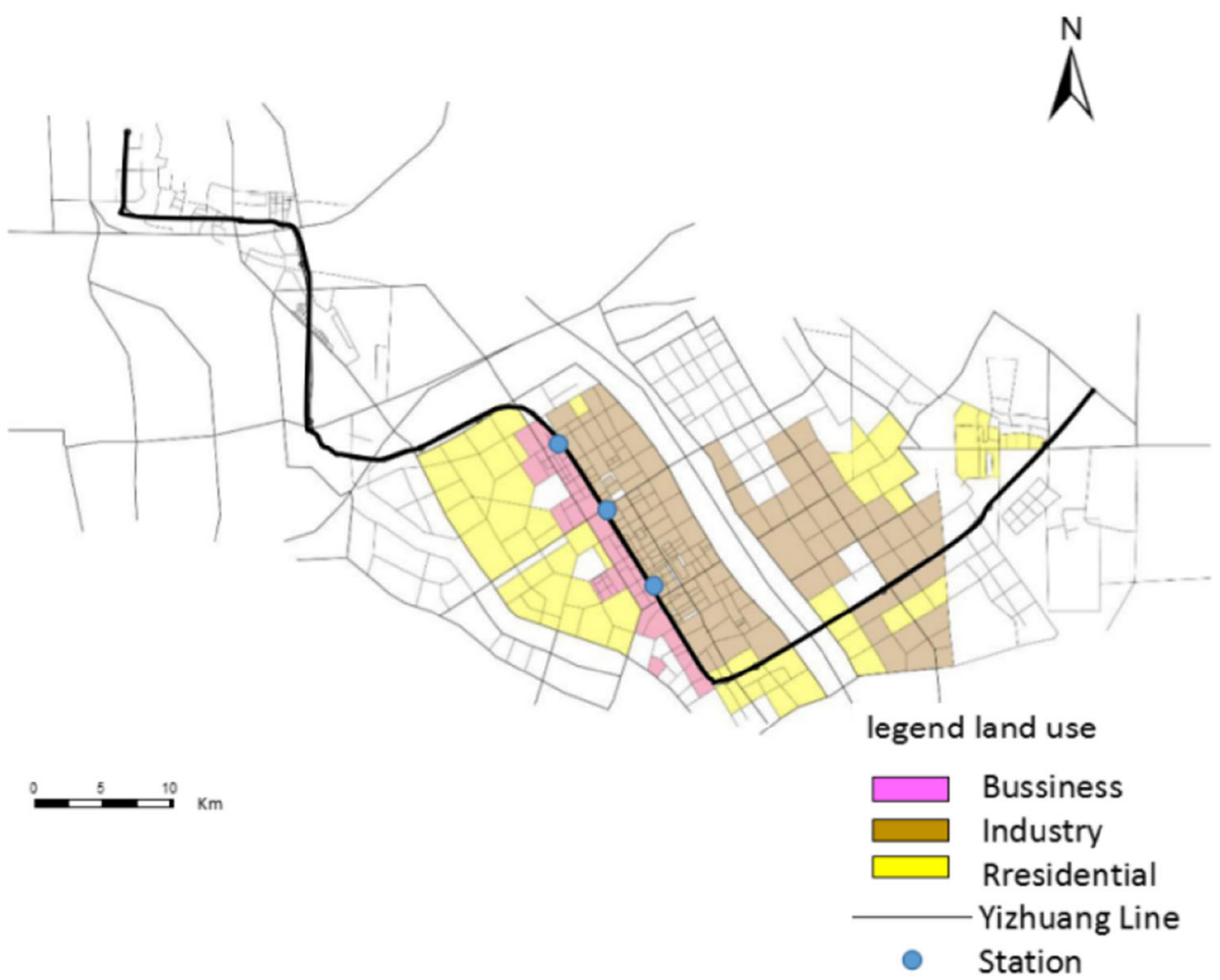

Ideal state
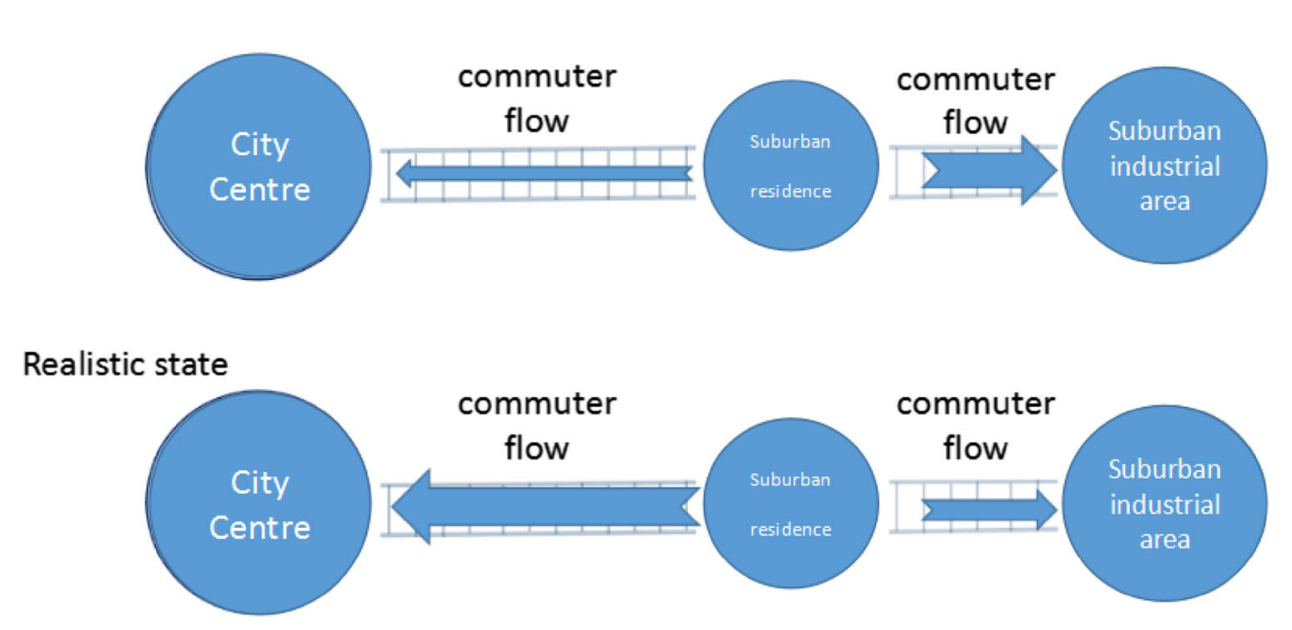

Fig. 7 Planned (above) and actual (below) commuting pattern population and jobs from city center, due to the mismatch between the existing low-skilled job opportunities and the high-skilled residents in the area as illustrated in Fig. 7.

The policy implication for this study is that the urban planning code for land use should be flexible and adaptable to the transportation infrastructure in TOD model. While there are many successful cases in China, the case of Yizhuang may not be considered as one. Our findings suggest that applying the concept of TOD into light rail development is not entirely straightforward, and instead an integrated approach between rail transportation and land use may be more successful. Proper land use is essential in successful TOD development, and to single-handedly focus on urban rail line development does not automatically lead to a successful TOD model in surrounding areas. Surrounding area naturally grows in a TOD way. Transportation and land use coordination are critical in implementing integrated planning. Additional studies on activity based and demand driven may be needed to further explore the needs for transportation and land use integration. 
Acknowledgements This study was supported by the National Nature Science Foundation of China (41401651, 51678029).

Open Access This article is distributed under the terms of the Creative Commons Attribution 4.0 International License (http://crea tivecommons.org/licenses/by/4.0/), which permits unrestricted use, distribution, and reproduction in any medium, provided you give appropriate credit to the original author(s) and the source, provide a link to the Creative Commons license, and indicate if changes were made.

\section{References}

1. Dueker K, Bianco M (1999) Light-rail-transit impacts in Portland: the first ten years. Transp Res Rec J Transp Res Board 1685:171-180

2. Bookout W (1992) Neotraditional town planning: a new vision for the suburbs? Urban Land 51(1):20-26

3. Bookout W (1992) Neotraditional town planning: cars, pedestrians, and transit. Urban Land 51(2):10-15

4. Bernick M, Cervero R (1997) Transit villages in the 21st century. McGraw-Hill, New York, pp 377-398

5. Calthorpe PG, Fulton WB (eds) (2001) The regional city: planning for the end of sprawl. Books. In: The regional city: planning for the end of sprawl. Island Press, New York, pp 107-139

6. Ewing R, Rong F (2008) The impact of urban form on US residential energy use. Hous Policy Debate 19(1):1-30

7. Dittmar H, Ohland G (eds) (2012) The new transit town: best practices in transit-oriented development. Island Press, New York, pp 99-111

8. Cervero R, Arrington GB, Smith-Heimer J et al (2004) Transit Oriented Development in America: experiences, challenges, and prospects, TCRP report 102. Transportation Research Board, Washington

9. Brown Barbara B, Cropper Vivian L (2001) New urban and standard suburban subdivisions: evaluating psychological and social goals. J Am Plan Assoc 67(4):402-419

10. William R (2008) From local to global: one hundred years of neighborhood planning. J Am Plan Assoc 75(2):209-230

11. Lin JJ, Gau CC (2006) A TOD planning model to review the regulation of allowable development densities around subway stations. Land Use Policy 23(3):353-360

12. Ministry of Housing and Urban-Rural Development (2016) Notice of the Ministry of Housing and Urban-Rural Development, the National Development and Reform Commission, and the Ministry of Finance on the Development of Featured Towns, No. 147

13. Parker T et al (2002) Statewide transit-oriented development study: factors for success in California. Final report. California Department of Transportation, Urban Land Institute, Washington

14. Zhao P, Lü B (2009) Transportation implications of metropolitan spatial planning in mega-city Beijing. Int Dev Plan Rev 31(3):235-261

15. Zhang C, Man J (2015) Examining job accessibility of the urban poor by urban metro and bus: a case study of Beijing. Urban Rail Transit 1(4):183-193

16. Wang J, Jin F, Mo H et al (2007) Research on review of TOD development mode analysis. Transp Transp Acad J 12(z2):19-22 (in Chinese)

17. Ma L, Wu F (eds) (2005) Restructuring the Chinese city: diverse processes and reconstituted spaces. In: Restructuring the Chinese city: changing society, economy and space. Routledge, London, pp $1-20$

18. Beijing Master Planning (2004) Final Report Beijing municipal government and Beijing urban planning Bureau, Beijing. http:// zhengwu.beijing.gov.cn/ghxx/ztgh/. Retrieved on Mar 12017. 